\title{
PEMANFAATAN INTERNET OF THINGS DALAM RANCANG BANGUN SISTEM INFORMASI PENGAWASAN BUS PADA TERMINAL BUS BERBASIS ARDUINO UNO DAN NODE MCU
}

\author{
Farhan Adiandoro $^{1)}$, Ericks Rachmat Swedia ${ }^{2)}$, Maulana Mujahidin ${ }^{3)}$, dan Margi Cahyanti ${ }^{4)}$ \\ 1,3 Jurusan Sistem Komputer, Fakultas Ilmu Komputer dan Teknologi Informasi, Universitas Gunadarma \\ ${ }^{2}$ Jurusan Teknik Informatika, Fakultas Teknologi Industri, Universitas Gunadarma \\ ${ }^{4}$ Jurusan Sistem Komputer, Fakultas Ilmu Komputer dan Teknologi Informasi, Universitas Gunadarma \\ $1,2,3,4$ Jalan Margonda Raya Pondok Cina, Depok, 16424 \\ E-mail : adiandroo@yahoo.com ${ }^{1)}$, ericks_rs@staff.gunadarma.ac.id ${ }^{2)}$, mujahidin@staff.gunadarma.ac.id ${ }^{3)}$, \\ margi@staff.gunadarma.ac.id ${ }^{4)}$
}

\begin{abstract}
ABSTRAK
Keberadaan bus di dalam terminal bus sendiri terkadang membuat penumpang kesulitan mencari informasi yang pasti. Seperti contohnya pada saat penumpang masih di perjalanan menuju terminal bus, penumpang tidak mengetahui apakah bus yang ingin dinaiki sudah datang atau belum. Atau pada saat penumpang menunggu di terminal bus terkadang penumpang tidak tau apakah bus yang penumpang ingin naiki sudah datang atau belum. Dengan semakin berkembangnya teknologi dan meningkatnya penumpang bus, maka diperlukan suatu sistem informasi untuk menunjukkan keberadaan bus yang ada di suatu terminal bus. Alat ini menggunakan mikrokontrolermikrokontroler Arduino Uno sebagai komponen pengendali dan NodeMCU dan memakai beberapa komponen yang digunakan adalah RFID dan motor servo. Penelitian ini melakukan penampilan informasi ketersediaan bus dan data bus seperti rute tujuan, waktu dan keterangan pada website secara realtime, dan mengukur respons waktu untuk mengubah database pada website menggunakan ISP CBN Google Station dan provider $34 \mathrm{G}$. Hasil rata-rata respons waktu yang diperoleh pada penelitian ini 2,0167 detik untuk CBN Google Station dan 2,083 detik untuk provider 3 4G. Penelitian ini telah berhasil memantau halte melalui sistem monitoring bus pada website secara real-time.
\end{abstract}

Kata Kunci: Arduino Uno, NodeMCU, Internet of Things, RFID, Servo, Website

\section{PENDAHULUAN}

Terminal bus merupakan tempat pemberhentian bus yang di mana dipertemukannya antara penumpang dengan bus. Keberadaan terminal bus di kota-kota besar di Indonesia memiliki permasalahan tersendiri, seperti keberadaan bus di dalam terminal bus dan letak parkir untuk memudahkan sopir untuk parkir. Keberadaan bus di dalam terminal bus sendiri terkadang membuat penumpang kesulitan mencari informasi yang pasti. Seperti contohnya pada saat penumpang masih di perjalanan menuju terminal bus, penumpang tidak mengetahui apakah bus yang ingin dinaiki sudah datang atau belum. Atau pada saat penumpang menunggu di terminal bus terkadang penumpang tidak tahu apakah bus yang penumpang ingin naiki sudah datang atau belum.

Oleh karena itu diperlukan suatu sistem informasi di mana penumpang mendapatkan informasi tentang keberadaan bus di suatu terminal dan sopir pun mendapatkan informasi di mana tempat parkir busnya agar tidak terjadi waktu tunggu yang lama dalam menaikkan dan menurunkan penumpang.

Dengan semakin berkembangnya teknologi dan meningkatnya penumpang bus, maka diperlukan suatu sistem informasi untuk menunjukkan keberadaan bus yang ada di suatu terminal bus. Sehingga memudahkan penumpang dalam mengecek apakah bus yang mereka tunggu apakah sudah sampai atau belum tiba. Di era globalisasi saat ini, perkembangan ilmu pengetahuan dan teknologi sangat pesat, khususnya yaitu perkembangan internet.

Penelitian tentang sistem keamanan area parkir di STKIP PGRI Tulungagung berbasis RFID, dalam penelitian ini kartu tag RFID digunakan sebagai kunci untuk membuka gerbang (Eko, 2019).

Sama halnya dengan penelitian tentang Prototipe Pintu Gerbang UNJANI yang juga menggunakan RFID Berbasis mikrokontroler untuk keluar masuk kendaraan (Kusnandar, N.K.H.D. dan Andreawan, S., 2019).

Pada penelitian mendesain sistem parkir berbasis RFID, di mana kartu tag RFID dijadikan sebagai kunci untuk membuka gerbang parkit dan memberikan informasi tentang kondisi ketersediaan tempat parkir (Agustin, M., Mekongga, I., Admirani, I. \& Azro, I., 2019).

Meneliti tentang efisiensi pemanfaatan RFID yang ditanamkan pada kartu mahasiswa, di mana kartu ini bisa berfungsi sebagai autentifikasi mahasiswa untuk memanfaatkan lahan parkir di area kampus (Mulyatun, S. dan Choirul, A.F., 2019). 
Penelitian yang berbasis web yang dijadikan sebagai referensi tentang aplikasi Gerbang Absensi Siswa Berbasis Web dan Arduino di SMK Negeri Kare, dalam penelitian ini kartu siswa yang terdapat tag RFID digunakan sebagai identitas siswa untuk mengabsen dan di masukan dalam database yang bisa di lihat oleh guru pada web tetapi masih bersifat jaringan lokal (Pratama, B. \& Riyanto, S., 2020).

Pada penelitian tentang sistem kendali pada pagar jalur bus Transjakarta menggunakan RFID berbasis internet of things di mana informasi keberadaan bus bisa diketahui dari RFID yang terdeteksidi setiap pagar jalur bus, dan dikirim ke web untuk memberikan informasi keberadaan bus (Nugroho, A.K dan Al Farisi, S., 2019).

Penelitian dengan memanfaatkan teknologi Internet Of Things (IoT) pengawasan pada budidaya ikan lele secara online memudahkan pemilik dan petugas untuk memantau kolam. Dengan memberikan informasi mengenai $\mathrm{pH}$ dan suhu air, pemberian pakan otomatis sesuai jadwal, pengisian air pada kolam dan daya listrik alternatif secara langsung (Firdaus, 2019).

Berdasarkan uraian permasalahan tersebut maka dibutuhkan sistem informasi untuk penumpang bus agar tidak terjadi waktu tunggu yang lama antara armada bus dengan penumpang. Alat yang digunakan yaitu RFID reader dan motor servo berbasis mikrokontroler. mikrokontroler adalah suatu Central Processing Unit $(C P U)$ yang terdiri dari tiga bagian yaitu unit pengendali, unit aritmatika, dan unit logika. Unit pengendali untuk mengatur urutan operasi seluruh sistem pada saat pengambilan pengkodean dan melaksanakan instruksi seluruh program yang tersimpan pada suatu memori.

Alat ini juga dilengkapi dengan NodeMCU yang memiliki modul ESP8266 yang akan mengirim data bus dari tap kartu ke internet. RFID reader berfungsi untuk tap kartu pada pintu masuk dan keluar terminal untuk membuka motor servo dan mengirim data bus ke internet. Motor servo berfungsi sebagai palang pintu masuk atau keluar terminal bus yang akan membuka dan menutup pintu masuk dan keluar.

\section{RUANG LINGKUP}

Dalam penelitian ini permasalahan mencakup. Perancangan dan pembangunan sistem pembacaan RFID dan pergerakan motor servo menggunakan Arduino UNO. Dan pengiriman data hasil pembacaan Arduino UNO ke internet menggunakan Node MCU.

\section{BAHAN DAN METODE}

Pada bagian ini akan dibahas hal hal yang di perlukan dalam pembangunan sistem.

\section{1 mikrokontroler}

mikrokontroler merupakan sebuah prosesor yang digunakan untuk kepentingan kontrol seperti yang terlihat pada gambar 1. Meskipun mempunyai bentuk yang jauh lebih kecil dari suatu komputer pribadi dan komputer mainframe, mikrokontroler dibangun dari elemen-elemen dasar yang sama. Seperti umumnya komputer, mikrokontroler adalah alat yang mengerjakan instruksi-instruksi yang diberikan kepadanya. Artinya, bagian terpenting dan utama dari suatu sistem terkomputerisasi adalah program itu sendiri yang dibuat oleh seorang programmer. Program ini menginstruksikan komputer untuk melakukan tugas yang lebih kompleks yang diinginkan oleh programmer.

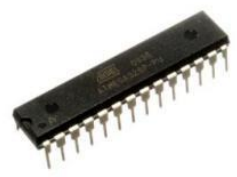

Gambar 1. mikrokontroler ATMega328

\subsection{Arduino}

Program board Arduino, dibutuhkan aplikasi IDE dari (Integrated Developtment Enviroenment). Melalui software inilah Arduino dilakukan pemrograman untuk melakukan fungsi-fungsi melalui sintak pemrograman. Arduino menggunakan bahasa pemrograman sendiri yang menyerupai Bahasa C. Bahasa pemrograman Arduino (Sketch) sudah dilakukan perubahan untuk memudahkan pemula dalam melakukan pemrograman dari bahasa aslinya. IC mikrokontroler Arduino telah ditanamkan suatu program bernama Bootlader yang berfungsi sebagai penengah antara compiler Arduino dengan mikrokontroler. Arduino IDE dibuat dari bahasa pemrograman JAVA. Arduino IDE juga dilengkapi dengan library $\mathrm{C} / \mathrm{C}++$ yang biasa disebut Wiring yang membuat operasi input dan output menjadi lebih mudah. Arduino IDE ini dikembangkan dari software processing yang dirombak menjadi Arduino IDE khusus untuk pemrograman dengan Arduino (Santoso, 2015).

\subsection{Arduino Uno}

Papan Arduino Uno merupakan papan mikrokontroler yang berukuran kecil atau dapat digambarkan sebagai suatu rangkaian berukuran kecil yang di dalamnya terdapat komputer berbentuk suatu chip. Gambar 2 menunjukkan sebuah papan Arduino dengan beberapa bagian komponennya (Rohman, 2015).

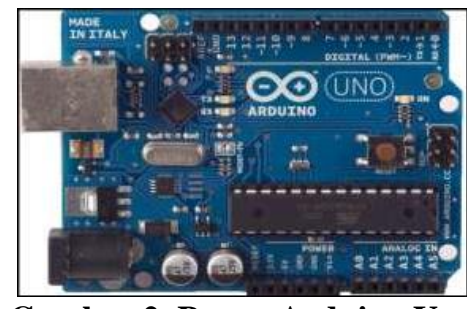

Gambar 2. Papan Arduino Uno

Arduino menggunakan bahasa $\mathrm{C}$ walaupun banyak sekali terdapat bahasa pemrograman tingkat tinggi (high level language) seperti Pascal, Basic, Cobol, dan lainnya. 


\subsection{NodeMCU}

NodeMCU merupakan papan pengembangan produk Internet of Things (IoT) yang berbasiskan FirmwareeLua dan System on a Chip (SoC) ESP8266-12E. ESP8266 sendiri merupakan chip WiFi dengan protocol stack TCP/IP yang lengkap (Wagyana dan Zulhelman, 2016).

\subsection{RFID (Radio Frequency Identification)}

RFID adalah sistem identifikasi tanpa kabel yang memungkinkan pengambilan data tanpa harus bersentuhan seperti barcode dan magnetic card seperti ATM. RFID merupakan suatu teknologi yang memanfaatkan frekuensi radio sebagai identifikasi terhadap suatu objek. RFID dapat dipandang sebagai salah satu cara dalam pelabelan suatu objek. Pelabelan dalam hal ini menggunakan sebuah kartu RFID atau TAG yang ditempatkan pada objek yang di identifikasi. Fungsi TAG sama dengan fungsi barcode label akan tetapi RFID mempunyai kelebihan daripada label barcode (Syahwil, 2017).

\subsection{IoT (Internet $\mathrm{O} f$ Things)}

Internet of Things (IoT) adalah suatu struktur di mana objek, orang, disediakan dengan identitas eksklusif dan kemampuan untuk melakukan perpindahan data melalui jaringan tanpa memerlukan dua arah antara manusia ke manusia, yaitu sumber ke tujuan atau interaksi manusia ke komputer (Burange \& Misalkar, 2015).

\subsection{PHP (PHP: Hypertext Preprocessor)}

PHP adalah singkatan dari Hypertext Preprocessor, yaitu bahasa pemrograman script server-side yang digunakan secara luas untuk penanganan pembuatan dan pengembangan sebuah situs web dan bisa digunakan bersamaan dengan HTML. PHP diciptakan oleh Rasmus Lerdorf pertama kali tahun 1994. Pada awalnya PHP adalah singkatan dari Personal Home Page Tools. Selanjutnya diganti menjadi FI (Forms Interpreter). Sejak versi 3.0, nama bahasanya ini diubah menjadi Hypertext Preprocessor dengan singkatannya PHP (Suja, 2014).

\subsection{MySQL}

MySQL adalah sebuah perangkat lunak sistem manajemen basis data SQL (database management system) atau DBMS yang multithread, multi-user, dengan sekitar 6 juta instalasi di seluruh dunia. MySQL AB membuat MySQL tersedia sebagai perangkat lunak gratis di bawah lisensi GNU General Public License (GPL), tetapi mereka juga menjual di bawah lisensi komersial untuk kasus-kasus di mana penggunaannya tidak cocok dengan penggunaan GPL (Suja, 2014).

\subsection{Motor Servo}

Motor servo adalah sebuah perangkat sebagai aktuator putar (motor) yang dirancang dengan sistem kontrol umpan balik loop tertutup (servo), sehingga dapat di set-up atau di atur untuk menentukan dan memastikan posisi sudut dari poros output motor. Motor servo merupakan perangkat yang terdiri dari motor DC, serangkaian gear, rangkaian kontrol dan potensiometer. Serangkaian gear yang melekat pada poros motor DC akan memperlambat putaran poros dan meningkatkan torsi motor servo, sedangkan potensiometer dengan perubahan resistansinya saat motor berputar berfungsi sebagai penentu batas posisi putaran poros motor servo. Penggunaan sistem kontrol loop tertutup pada motor servo berguna untuk mengontrol gerakan dan posisi akhir dari poros motor servo (Damayanti, 2016).

\section{PEMBAHASAN}

Perancangan program rancang bangun sistem monitoring informasi bus pada terminal bus berbasis internet of things dengan Arduino Uno dan NodeMCU ini terdiri dari beberapa tahap. Diawali dengan diagram blok dari sistem, perancangan alat, pembuatan flowchart selanjutnya Souce Code Arduino Uno dan NodeMCU dibuat menggunakan Arduino IDE dan Source Code pemrograman PHP dan MySQL dibuat menggunakan Visual Studio Code. Program Arduino dan NodeMCU ini akan menjalankan perintah-perintah pada alat ini, kemudian semua perintah Upload ke mikrokontroler dengan menggunakan media kabel USB. Sedangkan program PHP dan MySQL akan digunakan sebagai program website dari perancangan alat ini.

\subsection{Perancangan Alat}

Pembuatan sistem monitoring informasi terminal bus ini melalui beberapa tahap pembuatan. Pertama dibuat dulu diagram blok seperti gambar 3 .

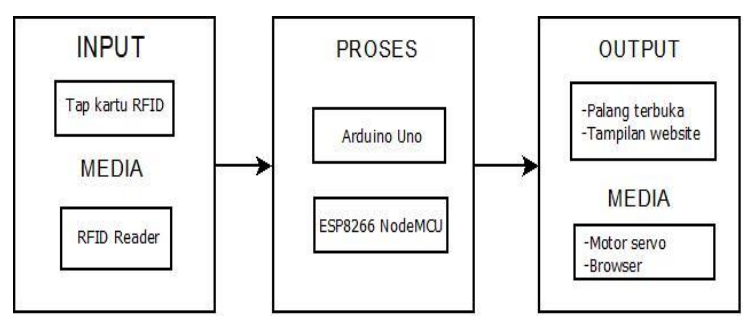

Gambar 3. Blok Diagram

Dari diagram blok terlihat RFID sebagai input, RFID ini terdiri atas 2 RFID yang dipasang pada gate masuk dan gate keluar, kedua masukan ini akan di proses oleh Arduino UNO untuk membuka palang pintu, dan mengirim data ke Node MCU untuk mengirimkan data ke web server, setelah itu adalah membuat rangkaian skematis elektronik di mana pada mikrokontroler Arduino Uno dihubungkan ke beberapa komponen lainnya seperti RFID reader dan motor servo.

Lalu dipersiapkanlah alat dan bahan yang akan digunakan, seperti penyusunan wiring arduino. Langkah berikutnya adalah meletakkan komponen-komponen elektronika agar dapat memudahkan dan penyesuaian sistem dalam penggunaannya. Lalu lengkah berikutnya 
adalah pembuatan pemrograman pada website dengan PHP dan MySQL.

\subsection{Pembuatan Rangkaian}

Tahap pembuatan rangkaian ini adalah dengan mempersiapkan komponen yang akan digunakan seperti Arduino Uno, NodeMCU. Rangkaian ini ditambahkan dengan adanya RFID reader sebagai tempat untuk tap kartu RFID, motor servo sebagai palang pintu dan tampilan website yang berfungsi sebagai tempat pemberitahuan informasi bus pada terminal bus. Gambar rangkaian bisa diliat pada gambar 4 .

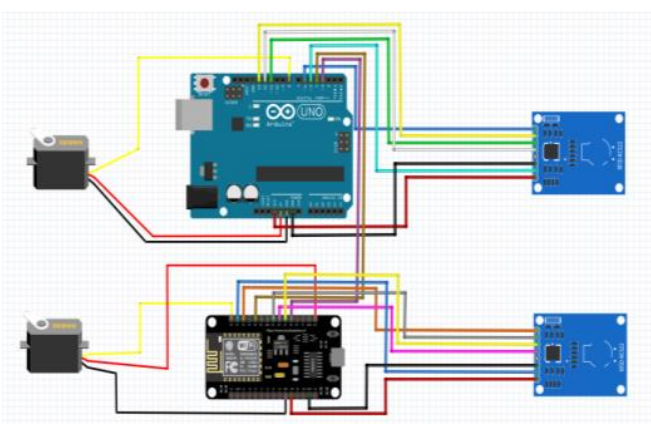

Gambar 4. Rangkaian Alat

\subsection{Struktur Kerja Alat}

Struktur kerja alat akan menjelaskan cara kerja alat dari input hingga menghasilkan output pada gambar 5 .

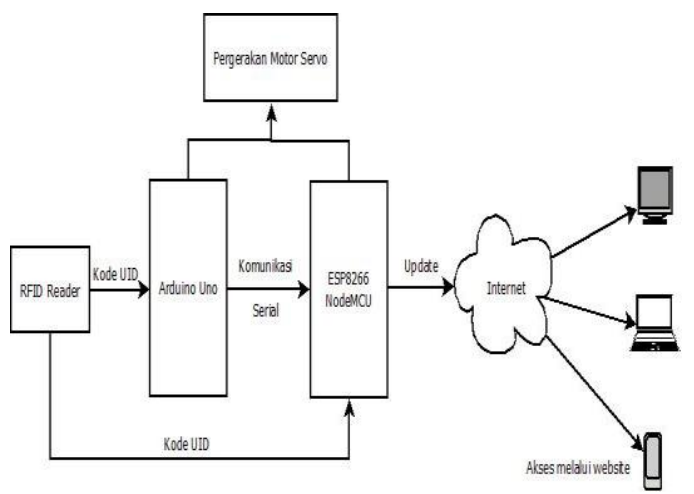

Gambar 5. Struktur Kerja Alat

RFID reader akan membaca kode UID. Kode tersebut diubah menjadi variabel String dan diberi nama strID. Selanjutnya, variabel string strID akan ditambahkan kalimat string lainnya. String ini yang digunakan untuk memperbarui database pada website. Untuk string strID di tambahkan setelah kalimat "alamat web". Variabel string ini akan di kirim ke NodeMCU dari Arduino Uno untuk memperbarui website. Untuk di NodeMCU, pada saat ada kartu yang di tap melalui RFID yang disambung ke pin NodeMCU akan langsung menyatukan variabel string strID, yang akan langsung dikirim ke internet untuk memperbarui website.

Setelah UID dari RFID di proses oleh mikrokontroler, motor servo akan bergerak $90^{\circ}$ yang berfungsi seperti palang/gate pada pintu masuk dan keluar terminal, lalu setelah palang menutup NodeMCU akan mengirimkan URL data ditambah string strID ke internet untuk mengupdate data pada website.

Arduino Uno dan NodeMCU melakukan komunikasi serial. NodeMCU akan menerima variabel string tersebut dan menuju ke alamat link dari string yang diberikan Arduino tersebut.

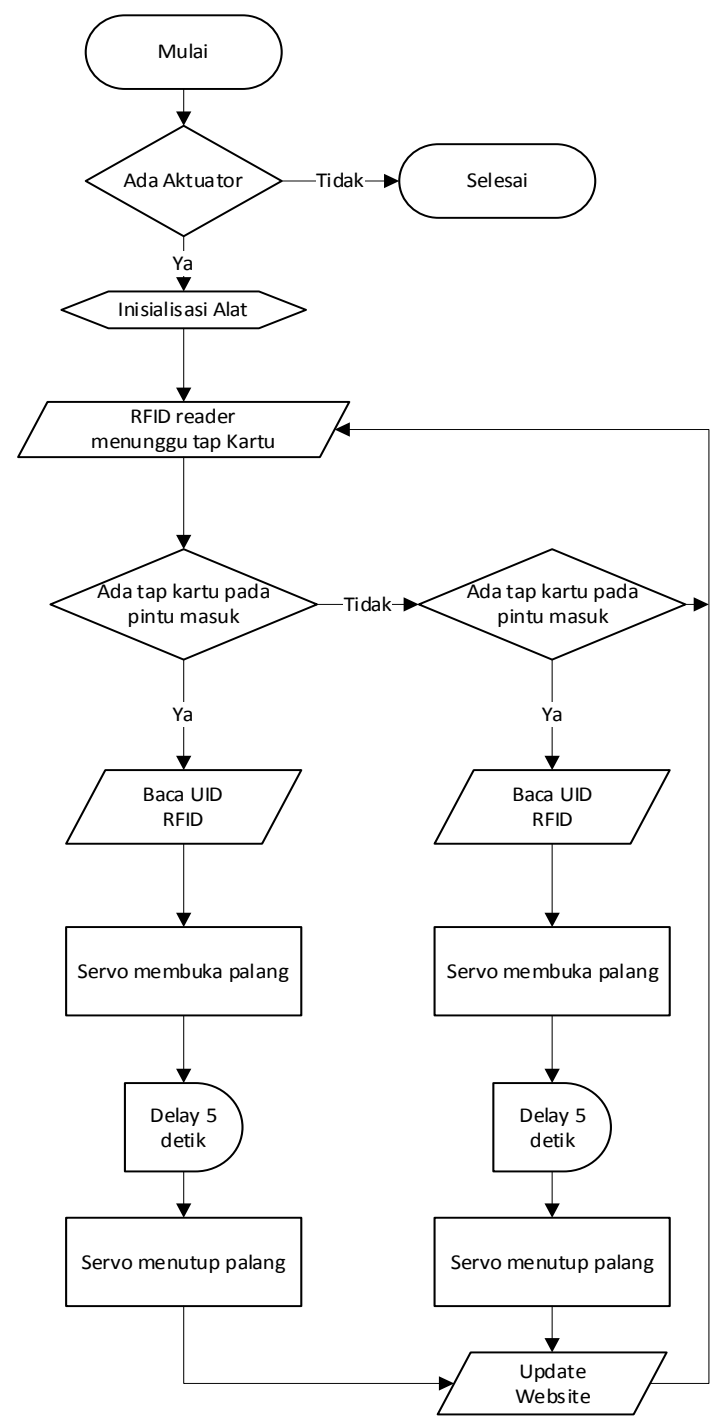

\section{Gambar 6. Flowchart Sistem Monitoring Informasi Bus}

\subsection{Flowchart}

Gambar 6 merupakan flowchart sistem atau bagan alir sistem di mana sistem pertama kali dijalankan, sistem akan melakukan proses inisialisasi perangkat input/output yang digunakan untuk menghubungkan dengan perangkat luar seperti RFID reader dan motor servo.

mikrokontroler akan melakukan proses pembacaan RFID reader, jika terdeteksi ada kartu RFID yang di tap pada reader RFID pada pintu masuk, selanjutnya RFID 
reader akan membaca UID RFID tersebut dan akan membuka palang pintu masuk dan akan mengirim URL ke website terminal bus yang akan memperbarui data kedatangan bus pada website dan akan kembali menunggu lagi tap kartu RFID selanjutnya pada pintu masuk.

Tetapi jika tidak ada tap kartu pada pintu masuk, akan mengecek apakah ada tap kartu pada pintu keluar. Jika ada selanjutnya RFID reader akan membaca UID RFID tersebut dan akan membuka palang pintu keluar dan akan mengirimkan URL ke website terminal bus yang akan memperbarui data kedatangan bus pada website dan akan kembali menunggu lagi tap kartu RFID selanjutnya pada pintu keluar.

\subsection{Implementasi}

Rancang bangun sistem monitoring informasi bus pada terminal bus berbasis internet of things dengan Arduino Uno dan NodeMCU ini menggunakan RFID reader berbasis mikrokontroler dengan motor servo yang merupakan rancangan alat untuk memberikan informasi data bus yang ada pada terminal pada terminal bus dengan sistem palang pintu agar hanya bus yang memiliki kartu saja yang bisa masuk ke terminal bus.

Penggunaan alat ini akan berjalan otomatis berdasarkan perintah-perintah atau source code yang ditanamkan ke dalam mikrokontroler tersebut. RFID reader yang dipasang pada alat ini dengan penempatan pada pintu masuk dan keluar terminal bus dan motor servo yang ditempatkan pada pintu masuk dan keluar terminal juga.

Sistem ini memiliki 2 komponen output yaitu pergerakan motor servo dan tampilan pada website. Pergerakan motor servo terjadi saat sudah ada kartu RFID yang di tap dan pengiriman data bus ke website untuk memunculkan informasi bus yang masuk ke website dan penghapusan data bus pada website saat kartu RFID di tap pada pintu keluar terminal.

Tampilan maket rancang bangun bisa dilihat pada gambar 7 terlihat pembaca RFID pada bagian luar.

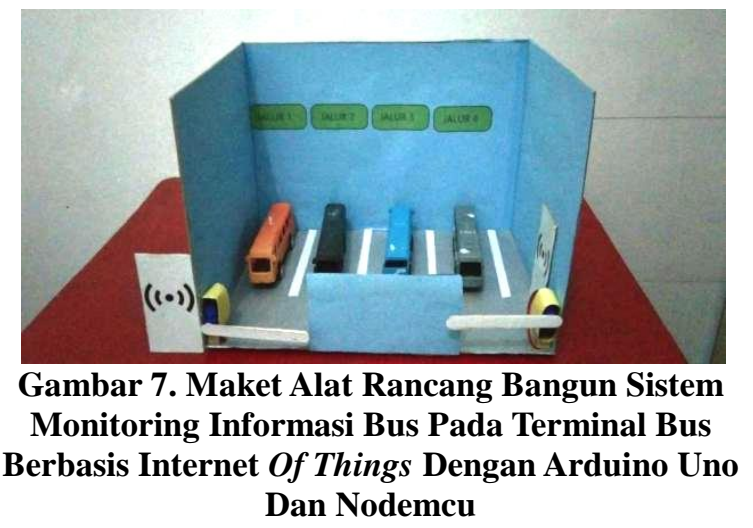

Ketika kartu RFID yang di tap pada RFID reader pada pintu masuk, maka RFID reader akan membaca
UID dari kartu RFID tersebut. Setelah dibaca lalu motor servo akan bergerak $90^{\circ}$ untuk membuka palang pintu masuk dan diberikan delay 5 detik untuk bus masuk ke dalam terminal. Setelah 5 detik, motor servo akan menutup palang lalu kode UID akan dikirimkan oleh Arduino Uno ke NodeMCU melalui transmisi serial. Sebelum URL untuk memperbarui website dikirim ke internet, UID dari Arduino Uno akan digabung dengan URL untuk memperbarui data pada website. Proses selanjutnya URL yang telah digabung akan dikirim ke internet melalui koneksi internet dari NodeMCU yang nanti akan memperbarui data ketersediaan bus di terminal pada website. Jika sudah di-update, RFID reader akan kembali siap untuk membaca tap kartu RFID selanjutnya. Tampilan web ketika ada bis masuk terminal bisa dilihat pada gambar 8 . Waktu respons yang dibutuhkan dari palang tertutup sampai data keluar di web adalah rata - rata 2,8 detik, sedangkan jarak maksimal antara kartu tag dan pembaca RFID adalah $2 \mathrm{~cm}$.

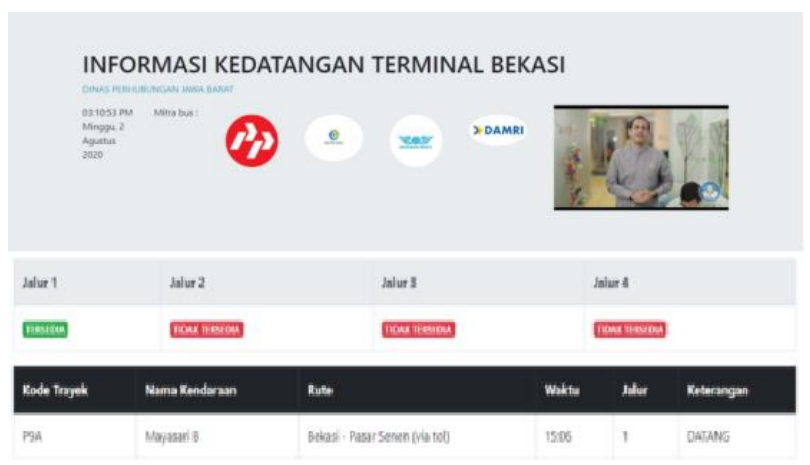

\section{Gambar 8. Tampilan Website Setelah di Tap Kartu RFID Pada Pintu Masuk}

Dan ketika kartu RFID yang di tap pada RFID reader pintu keluar, maka RFID reader akan membaca UID dari kartu RFID tersebut. Setelah dibaca lalu motor servo akan bergerak $90^{\circ}$ untuk membuka palang pintu keluar dan diberikan delay 5 detik untuk bus keluar terminal.

Setelah 5 detik, motor servo akan menutup palang lalu kode UID dari kartu RFID akan diproses oleh NodeMCU untuk digabungkan dengan URL yang akan dikirim ke internet. UID yang dibaca oleh RFID reader pintu keluar akan digabung dengan URL untuk memperbarui data pada website, Setelah digabung lalu proses selanjutnya URL yang telah digabung akan dikirim ke internet melalui koneksi internet dari NodeMCU yang nanti akan memperbarui data ketersediaan bus di terminal pada website. Jika sudah diupdate, RFID reader akan kembali siap untuk membaca tap kartu RFID selanjutya. Tampilan web Ketika bus menempelkan kartu pada saat keluar seperti terlihat pada gambar 9. Waktu respons yang dibutuhkan untuk mengeluarkan data ke website adalah rata - rata 2,8 detik dengan jarak maksimal $2 \mathrm{~cm}$. 


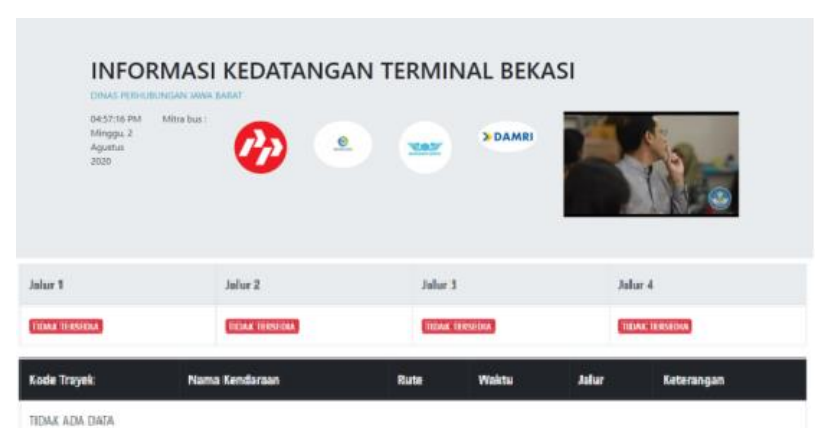

\section{Gambar 9. Tampilan Website Setelah Di Tap Kartu RFID Pada Pintu Keluar}

\section{KESIMPULAN}

Berdasarkan penelitian dan perancangan sistem bisa di tarik kesimpulan bahwa rangkaian kerja penelitian ini dapat diambil kesimpulan. Sistem ini bisa mengeluarkan informasi tentang kedatangan bus pada website, dengan respons waktu rata - rata 2,8 detik dan jarak maksimal pembaca bisa membaca kartu tag-nya adalah $2 \mathrm{~cm}$.

\section{SARAN}

Terdapat beberapa saran yang sangat berguna untuk tahap pengembangan selanjutnya, yaitu, tampilan website yang lebih menarik. seperti pendaftaran bus baru dan penambahan kode kartu RFID melalui website atau terdapat sistem pesan tiket/booking tiket melalui website. Memberikan tambahan perangkat GPS agar bus dapat di track posisinya dan dapat diketahui estimasi kedatangannya lewat website. Untuk keamanan pengiriman data sebaiknya diberikan enkripsi data agar website lebih aman. Pengembangannya dapat membuat lebih dari 1 terminal yang saling terintegrasi, sehingga butuh lebih banyak mikrokontroler dalam proses pembuatannya.

\section{DAFTAR PUSTAKA}

Agustin, M., Mekongga, I., Admirani, I. \& Azro, I., 2019. Desain sistem parkir berbasis RFID. JUPITER (Jurnal Penelitian Ilmu dan Teknologi Komputer), 11(1), pp.21-28.

Eko Prasetyo, I.A., \& Kartadie, R. 2019. Sistem Keamanan Area Parkir STKIP PGRI Tulungagung Berbasis Radio Frequency Identification (RFID). JoEICT (Journal of Education And ICT), 3(1).

Damayanti, R., 2016. Aplikasi Motor Servo Pada Prototipe Pintu Rumah Otomatis POLITEKNIK NEGERI SRIWIJAYA).

Firdaus, M.W., 2019. Pembangunan Prototipe Sistem Monitoring Lele Care Dengan Daya Listrik Menggunakan Lcd Thin Film Transistor (Tft) Touchscreen Berbasis Arduino Mega2560 (Doctoral dissertation, Alternatif Di Budidaya Bakti Mandiri (Doctoral dissertation, Universitas Komputer Indonesia).
Kusnandar, N.K.H.D. \& Andreawan, S., 2019. Perancangan Prototipe Pintu Gerbang UNJANI Keluar Masuk Kendaraan Menggunakan RFID Berbasis Mikrokontroller ATmega32

Mulyatun, S. \& Choirul, A.F., 2019. Efesiensi Penerapan Sistem Pendukung Pada Lahan Parkir Dengan Memanfaatkan RFID (Radio Frequency Identification) Pada Kartu Tanda Mahasiswa. INTECHNO Journal-Information Technology Journal, 1(2), pp.36-42

Nugroho, A.K. \& Al Farisi, S., 2019. Prototipe Sistem Kendali Pagar Jalur Transjakarta dengan Sensor Radio Frequency Berbasis Internet of Things. AUTOCRACY: Jurnal Otomasi, Kendali, dan Aplikasi Industri, 6(01), pp.22-26.

Pratama, B. \& Riyanto, S., 2020. Perancangan Aplikasi Gerbang Absensi Siswa Berbasis Web dan Arduino di SMK Negeri Kare (Studi Kasus Pada SMK Negeri Kare). DoubleClick: Journal of Computer and Information Technology, 3(2), pp.91-97

Rohman, A, Z, 2015, Rancang Bangun Alat Ukur Getaran Mesin Berbasis Arduino, Jurusan Teknik Elektro, Universitas Negeri Semarang.

Santoso, H, 2015, Panduan Praktis Arduino untuk Pemula. Diakses pada tanggal 12 April 2017 dari www.elangsakti.com

Suja, I. 2014. Pemrograman SQL dan Database server MySQL. Jakarta : Andi Publisher.

Syahwil, M. 2017. Panduan Mudah Belajar Arduino Menggunakan Simulasi Proteus. Jakarta: Andi Publisher.

Wagyana, A. \& Zulhelman, Z., 2016. Prototipe smart power outlet untuk pencegah kebakaran akibat arus listrik. SENTIA 2016, 8(2). 